Chapter 3.

\title{
Using Internet technologies as the foundation of organizational forms in introducing the constructivist blended learning approach to teaching English for Specific Purposes at tertiary schools
}

This chapter is devoted to analyzing the third and last basic constituent of the constructivist approach to designing ESP courses for students of tertiary educational institutions - blended learning. It has already been mentioned that the first two fundamental constituents - experiential interactive teaching/learning and content-based instruction - are quite equal in what concerns their significance for effective implementation of the constructivist approach (see Fig. 6). On the other hand, it was also mentioned that blended learning as such is not absolutely indispensable for introducing that approach. For instance, the first version of it we developed when elaborating the ESP course and coursebook (Business Projects) for future economists and businesspeople had experiential interactive teaching/ learning and content-based instruction at its base but without obligatory blended learning orientation. Blended learning was integrated into the approach only when developing the ESP course and coursebook for future psychologists. This particular aspect will be discussed in greater detail further.

In general, in the case under consideration, blended learning is meant only to support experiential interactive teaching/learning and content-based instruction, to improve them by making the teaching/learning process more intensified and efficient, thereby accelerating and facilitating language acquisition by students. Thus, blended learning is subordinated both to experiential interactive teaching/learning and to content-based instruction, as it is shown in Fig. 10.

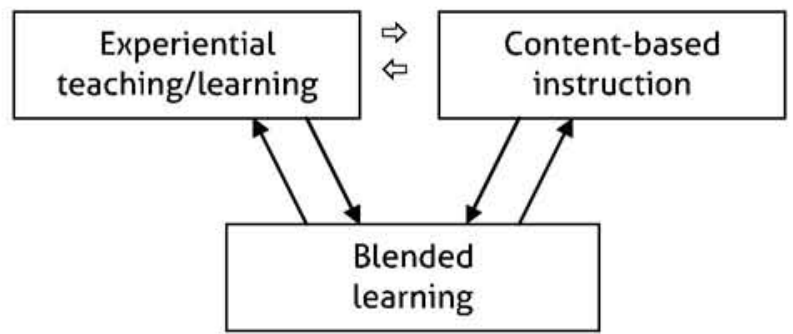

Fig. 10 The relations between experiential teaching/learning content-based instruction (as two equally significant constituent parts) and blended learning (as a subordinated constituent part) when implementing the constructivist approach to an ESP course design 
Blended learning, as it is clear from what was said in the Introduction, means using Internet technologies for language teaching and learning. There is nothing surprising in the subordinated position of such technologies in the constructivist approach discussed in this monograph. This is due to the very fact of their being only technologies, i.e., just tools in the process of language acquisition by students. The subordinated position of Internet technologies (and even broader - of all computer technologies) in second/foreign language teaching is current even in distance learning situations because achieving teaching and learning goals cannot be determined by tools alone, however sophisticated they may be. The attainment of those goals depends on the teachers, students, coursebook writers, on learning content, and on methods developed which determine how efficiently the tools (including the Internet) are used. In our case, it is such a method as experiential interactive teaching/learning and the learning content, whose selection procedure is dictated by content-based instruction requirements, that determine when, where, and how to use Internet technologies (blended learning) in the constructivist ESP course.On the other hand, nowadays the role played by Internet technologies in language teaching is so great that blended learning, which presupposes their mandatory use for facilitating and accelerating the target language acquisition, deserves to be postulated as one of the basic prerequisites for developing a genuinely up-to-date approach to designing ESP courses at tertiary schools. The possibilities provided by the Internet (to be discussed further in this chapter) for successful language learning, especially in what concerns its learning for professional communication, are so broad that no approach can be considered as fully adequate if those possibilities are neglected.

So, this chapter is intended to analyze how blended learning (Internet technologies) can help in implementing the constructivist approach in the framework of ESP courses taught at tertiary schools, i.e., how it (they) can help in ensuring the optimal and most successful implementation of experiential interactive teaching/learning method in the conditions when the learning content is selected following the content-based (theme-based) instruction's requirements to such selection. The chapter is also intended to analyze what modifications - in comparison with the descriptions in the two preceding chapters - in experiential interactive teaching/learning method and in content-based (theme-based) instruction are generated by the introduction of blended learning serving as an organizational tool for their practical implementation. But before discussing those issues, it is first necessary to analyze what place Internet technologies (and broader - computer technologies of which Internet technologies are only a part) occupy in today's language teaching and what opportunities they create for such teaching. 


\section{Computer and Internet technologies in target language teaching}

The analysis of how Internet technologies are and can be used in ESP teaching first requires at least a short description of using computer technologies in general in foreign/second language studies since the former is but the subdivision of the latter. However, it should be noted that it is probably the most important subdivision for our case because Internet technologies have become the peak point in employing computers for improving, facilitating, and accelerating language acquisition.

The history of computerization in foreign/second language studies started in the last decades of the $20^{\text {th }}$ century and got the name of CALL (Computer-Assisted Language Learning). Egbert (2005: 4) defined CALL as learning languages in whatever context with the aid of and by way of using computer technologies.

CALL has been developing gradually and a distinctive feature of this development has been the fact that the trends which manifested themselves from the very beginning are still active and have not been discarded as obsolete (as with a lot of other trends in foreign/second language teaching). For instance, the development of computer programs for teaching grammar was very popular at the very start of CALL when teaching aspects of language was in the focus of attention of computer programs' developers. But creating numerous grammar teaching programs continues even now, which can be seen in whatever most up-to-date computerized materials designed for training students in language skills required for taking international examinations in English, such as FCE, CAE, IELTS, TOEFL, and others.

In what concerns teaching target language vocabulary, the development of computer programs for that has even expanded with the appearance of corpus linguistics (Biber, Conrad, \&. Reppen, 2002). Corpus linguistics is aimed at determining all possible ranges of meanings and combinations of lexical units within a certain language. Utilizing special computer programs called concordancers, corpus linguistics is engaged in compiling corpora of actual uses of every given lexical unit and of its concordances - the list of possible combinations with other lexical units which makes clear all its possible meanings at the given stage of language development. It was soon discovered that compiling concordances of lexical units with the help of concordancer computer programs was quite accessible to language students and greatly facilitated and improved their vocabulary learning. This is why some experience has already been gained in teaching vocabulary by using the methods of corpus linguistics and relevant software (Fan, \& Xu, 2006; Römer, 2004). The approach is based on giving students some lexical corpora and providing them with relevant concordancer programs. Students are requested to compile concordance lines 
using that program and, on the basis of the concordance lines obtained, analyze the range of possible meanings, combinations, and usage of every lexical unit processed by them. The authors mentioned above have found that such an approach greatly contributes to improving and facilitating vocabulary acquisition by students - both for recognizing and understanding lexical units when reading and listening and for using them in speaking and writing. Besides, the approach is good for integrated teaching of vocabulary and grammar (Tribble, 2000).

There are also computer programs that teach pronunciation, especially target language intonation (students listen to the speaker and see the graphic patterns of his/her intonation on the screen; the aim of every learner is to try and imitate the intonation of the speaker in such a way that the graphic representation of his/ her own intonation on the screen coincides with that of the speaker). Though such programs are sometimes strongly criticized as being of very little avail (González, 2010: 101-102), their real efficiency is beside the point for our discussion. The important thing is that even in such an unlikely field as teaching pronunciation, computers and computer language teaching programs can find their use.

In what concerns the computer programs for teaching target language communication skills (reading, writing, speaking, and listening), early programs of that kind were oriented exclusively at teaching written communication: reading and writing. That was quite natural because until comparatively recently computers could not speak. But such programs continue to be actively developed now too - due to the importance for students of learning target language written communication and, primarily, due to the best adaptability of computer technologies for teaching just this type of communication.

Computer programs for teaching reading are the simplest to develop. This is why they are being developed in great numbers, and the issues of their development are thoroughly analyzed in professional literature (c.f. AlKahtani, \& Abalhassan, 1999: Chun, \& Plass, 1997, and a number of other authors). The relative simplicity of developing such programs is due to the fact that checking readers' (students') understanding of a text read by them on the computer screen can be done by making learners choose a correct response alternative out of several ones or by some other similar test-type assignments for checking understanding. This is absolutely within the range of what computers can do (even with giving explanations of the mistakes made if a wrong alternative has been selected) because in all such cases the choice is only binary - yes or no-which corresponds to the basic principle of computer operation. That is why in teaching target language reading computer programs can even replace teachers to some extent.

Computer programs for teaching target language writing need to be much more sophisticated because writing is a productive communicative activity, so checking the correctness of students' work by making them choose one alternative response out of several suggested is of no avail. However, in teaching writing various computer programs are used probably even wider than in teaching reading. 
Research has shown that their aid is incomparably valuable thanks to:

1. The opportunities given by the text processor because its use considerably facilitates, intensifies, and optimizes the development of writing skills due to creating conditions for multiple editing, amending, and improving the text being written by every particular student (Harmer, 2001; Slaouti, 2000).

2. The opportunities for accelerating and improving the development of students' spelling, punctuation, lexical, and even stylistic writing skills/ techniques due to the availability of an editing program in every text processor, that program helping writers to find their spelling, punctuation, lexical, and stylistic errors and providing them with some alternatives for their correction (Kern, 2006).

3. The opportunities for teachers of improving and facilitating their own work on checking and correcting their students' written pieces due to using the same facilities provided by the text processor (Slaouti, 2000).

4. The opportunities for developing special computer training programs for training (or even drilling) some standardized writing skills/elements, like those that abound in business correspondence (Storozhuk, 2004).

5. The opportunities of combining students' individual training (or even drilling) of some standardized writing skills/elements with the help of specific computer teaching programs and their collaborative work with the teacher and/or other students on more creative writing assignments.

All these advantages of computer-assisted teaching of target language writing has led to considering working on students' writing skills development without using computers as something inadmissible for an up-to-date writing classroom.

Comparatively recently, with the development of computer technologies, programs for teaching listening and speaking have appeared. In what concerns computer programs for teaching listening in the target language, they have become especially popular due to the broad teaching opportunities given by the multi-media nature of audio materials listened to through computers: combination of sound, video, photos, pictures, animation, music, and even graphic texts when they are useful (Kern, 2006). Numerous authors believe in great advantages of teaching listening with the help of computer programs (c.f., for instance, Motteram, 2000), especially with the help of computer digital video programs (Brett, 2000) as compared with traditional technical appliances used in teaching practice, such as cassette recorders, CD players, video, etc.

Computer programs for teaching target language speaking also exist and begin to spread (Motteram, 2000). However, in this case there is the same limitation as in teaching writing with the aid of computers: computer programs can be used only for teaching some standardized elements of speaking, as well as for giving speaking tasks and supplying prompts to learners. More creative, genuinely productive, assignments need to be done in live communication - with the 
teacher, other students, etc. But even in their auxiliary function computer programs for teaching target language speaking skills can be a great help in intensifying the development of those skills.

Computer programs have also started playing an increasing role in teaching the cultural aspects of communication and, in general, in teaching the target language culture (Kern, 2006). This role has especially gained significance after the emergence of the Internet (Thorne, \& Thorne, 2000). The cause is due to the fact that nothing else can supply such an abundance and variety of cultural information ready for use in the teaching/learning process.

Finally, computerized testing as one of the most important component parts of CALL cannot be forgotten (Filcher, 2000; Harmer, 2001). The advantages of computer-based testing over the paper-based one in what concerns its efficiency, providing for mass testing of great numbers of candidates at once, comparative cheapness, objectivity, automated checking of test results, and opportunities of informing the examinees about those results not only immediately after testing but even in the process of testing itself are so great that computerized testing is gradually ousting the paper-based one in language teaching. And it is quite natural that some of the most prestigious international exams (tests) of English as a second/foreign language, such as TOEFL, are almost completely computerized.

Everything said above shows that there is not even one single aspect in teaching/learning second/foreign languages which is not embraced by the process of computerization of that teaching/learning - even without taking into account the Internet technologies to be discussed further. The computerization in question has such important advantages that up-to date language teaching can hardly be imagined without it. If we try to summarize those advantages (both those already discussed above and the ones to be first mentioned and explained below), their list should include at least:

1. Considerable intensification and optimization of students' acquisition of language skills (vocabulary, grammar, and pronunciation).

2. Considerable intensification and optimization of students' acquisition of communicative skills in reading, writing, listening, and speaking.

3. The opportunity of improving and making more authentic the study and acquisition of target language culture and the cultural and pragmatic communication norms characteristic of the target speech community (Hymes, 1974), i.e., serious help in the process of development of students' target sociolinguistic and pragmatic competences.

4. Raising the testing of students' competence in the target language to a much higher level of efficiency and objectivity, creating better opportunities for mass testing of great numbers of candidates at once and for automated checking of test results.

5. Creating opportunities for constant automatic collection and systematization of data related to every individual student's progress during all the 
period of his/her language learning (Chapelle, 1998) which is important for improving the organizational and administrative aspects of teaching.

6. The opportunity of using computer as a single technical device in the teaching/learning process which alone can replace all the other devices, such as cassette recorders, CD players, videos, TV, etc. Every computer can not only combine all the functions of those devices that are important for language teaching/learning. It can also surpass by far everything that all the other technical devices can do thanks to text processors, multi media, and everything else that computers have and the other technology does not.

7. Ensuring students' learning autonomy and teacher's pedagogical autonomy (Warschaver, 2002). In the Introduction and Chapter 1 of this monograph the issue of learning autonomy was discussed as one of the most important ones in creating conditions for more successful language acquisition and for more democratic and humanistic structuring of the pedagogical process (Benson, \& Voller, 1997; Dam, 2002). Only learning autonomy can develop the skills of learning efficiently and teach students to assume responsibility for their own learning. From this point of view, learners' work with computers is autonomous in its very nature, so when they use computers for language studies, it automatically develops their abilities of being autonomous in such studies. This is applicable to teachers too who, thanks to computers (especially to the Internet), get rid of the total dependence on the textbook(s) that they are using.

All these advantages of computerization in language studies allowed Warschauer, even before the avalanche-like spread of using Internet facilities in ESL/EFL teaching, to draw the conclusion that when we use computers in such studies "... we do not have old language learning plus the computer, but we have a different language learning" (Warschauer, 1998: 760). It is a new approach, a new stage in teaching and learning languages which creates opportunities for radically enhancing the efficiency of that teaching and learning ensuring far better learning outcomes.

It should be noted in passing that, since the introduction of computers into the process of teaching and learning languages has practically become an absolute necessity, the issue of ensuring language teachers' computer competence has come to the forefront (Warschauer, 2002).

That issue has become especially topical after the development of approaches to introducing Internet technologies into the process of second/foreign language teaching. If introducing computer language teaching programs had generated radical changes in that process, bringing Internet technologies into it gave rise to a real revolution. A number of opportunities were created that before had not existed at all. Those opportunities are so important for language teaching in general and for ESP teaching in particular that they deserve a special and detailed analysis. 
Warschauer and Whittaker (1997: 27) name four principal reasons for introducing the Internet technologies into language studies:

1. They contribute to language acquisition thanks to the linguistic nature of online communication. It was discovered that electronic discourse is more complicated in what concerns its lexical and syntactic characteristics than oral discourse (Warschauer, 1996a), and it also manifests very many specific characteristics of speech functions (Chun, 1994; Kern, 1995). It is obvious how important and useful these features of electronic discourse are for language and communication skills acquisition.

2. They ensure the best conditions for teaching target language writing because authentic audience for written communication is provided (Janda, 1995).

3. They ensure the enhancement of students' learning motivation (Warschauer, 1996b).

4. They ensure students' gaining command of the skills of working on the Internet in English - those skills that are very important for future career success. Students do not need Internet only for learning English. Sometimes, English is required for acquiring efficient skills of working on the Internet (Warschauer and Whittaker, 1997).

The authors who have just been quoted did not pay special attention in the particular work that has just been mentioned to one more very important reason of using the Internet in foreign/second language teaching and learning. This reason is discussed by Harmer (2001: 146) who says that the Internet is an inexhaustible source of information, especially of information in English which makes for its broadest use in the process of teaching/learning. Though this information is mostly authentic, i.e., prepared by target language native speakers for other native speakers, however, it can be used for teaching/learning purposes, especially in what concerns ESP teaching (see further).

This gives an opportunity not only to teachers to extract from the Internet inexhaustible materials in English that, being authentic in the above sense, can at the same time be used as materials for the teaching/learning process aimed at students' acquisition of English as a second/foreign language. Obtaining information in English from the Internet can be done by students themselves as well. They can work on procuring and processing that information either after receiving a relevant assignment from their teacher or totally independently. In this way, learners can greatly expand and improve their contacts with the target language through constantly using that language when visiting different Internet sites in English. It is obvious how important this is, especially for ESP teaching and learning, because authentic professional sites in English become one of the principal sources of students' materials for learning the target language. Outside professional target language environment/outside professional target language sources of information are also provided which is a requirement for designing a really interactive model of ESP teaching and learning (c.f. Chapter 1). 
Therefore, it can be asserted with confidence that the principal advantages of using the internet in ESP courses designed for tertiary schools are: 1) creating opportunities for teachers and authors/compilers of teaching materials to select (with no limitations) professional content-based authentic materials on professional Internet sites in English, thereby providing for the professional content-based orientation of the teaching/learning process as a whole; 2) creating opportunities for students of doing Internet research on professional Internet sites in English with the purpose of finding materials there for completing their learning assignments in the ESP course. This facilitates and accelerates students "self-constructing" their skills of professional target language communication. These two advantages, or two functions, of Internet technologies will be further considered as the principal ones for introducing the blended learning constituent into the constructivist approach to ESP teaching and learning.

The functions in questions were also considered among the principal ones in another publication by Warschauer and his co-authors (Warschauer, Shetzer, \& Meloni, 2000). In their work, the authors distinguished three principal functions of the Internet in learning English as L2:

1. Communication via the Internet and doing joint projects via the Internet. Communication via the Internet (e-mails, forums, chat rooms) can be with native speakers, the teacher, other students of English - from the same academic group, the same university, other universities in the same country, and from universities of other countries. Joint projects can be done in the same way, for instance, a project on researching the ecological situation in two big cities of two different countries. This project may result in writing a joint report that is presented by all participants. Presentations can be held simultaneously in the classrooms of different universities if the participants were working via the Internet only - with no live contacts and no opportunities of coming together for presenting the outcomes of the completed project. The intensive written communication required by such a project cannot but have a favorable impact on developing students' productive and receptive communication skills.

2. Information research on the Internet. This research provides students with numerous sources for completing their learning assignments (to be further discussed in this chapter). As already said, we consider just this function to be of primary importance and deserving to be mentioned first - though Warschauer, Shetzer, \& Meloni (2000) put it only in the second position. The prioritizing functional significance of Internet research in comparison with Internet communication is due to the fact that the former can be organized with no problems at all and can occupy a considerable place in everyday teaching/learning process. On the other hand, 
the latter may be used more episodically because it is much more difficult to organize.

3. Publication of students' works in the Internet network. If a group of students together with their teacher create their own web-page in English and the best students' works, such as essays, are published there, it creates additional and very strong stimuli for learners to improve their communication skills, especially their writing skills. This is because the web page can be accessed and read by many different people, not only the students themselves and their teacher. This creates broad potential readership for what the students have written - making them try and do their best in order to produce pieces of writing that could interest and attract all visitors to their web-page. Besides, in such a case, prerequisites are created for publishing students' own online journal in English which makes their English studies even more motivated uniting all learning efforts in the framework of one meaningful and creative communicative activity.

Sharma (2003) was one of the first to emphasize the greatest potential of the Internet in ESP teaching and learning, particularly in teaching and learning Business English. In his book co-authored by Barrett (Barrett, \& Sharma, 2003) one important point made by the authors was disclosing the interactive nature of using the Internet in ESP/Business English courses. According to them, such interactivity is obvious even in cases when the Internet is used for information research only. This feature is of cardinal importance in the context of our monograph in view of those characteristics of the approach suggested in it that were discussed in the first chapter. Interactivity distinguishing the work with the texts placed on the Internet from reading ordinary linear printed texts is manifested through:

- "choice of route through the material. This can be determined by the user, using hyperlinks to move off in different directions

- choice of media. The user can make decisions how many times to use an audio clip, or choose when and whether to access a video clip, etc.

- submission of answers or information. The learner fills in a form or completes an activity, submits this and receives some kind of feedback

- customising. The learner can input data and receive specific information" (Barrett, \& Sharma, 2003: 35).

Everything said in this section shows the great potential of using computer technologies, and Internet technologies among them, in language teaching. Since it is the Internet (in the framework of blended learning) that mostly interests us, the next issue to be discussed is the organizational structure of introducing Internet technologies into ESP courses at tertiary schools. 


\section{The organizational structure of introducing Internet technologies into ESP courses at tertiary schools}

A very logical organizational structure of using the Internet for teaching ESP/ Business English was suggested by Barrett and Sharma (2003: 38). They have divided the forms of using the Internet in such classes of English into two basic ones: on-line (in-class use directly during the lesson of English) and off-line (outof-class use with utilizing the materials found during the Internet search for doing later in-class assignments).

According to Barrett and Sharma (2003: 38), on-line lessons should consist of three main stages:

1. Pre-computer work. It is the period when the teacher sets the task for students to do when they are working with the computer.

2. Computer work. It is the period when students are directly involved in working on the Internet, mostly searching for some information there in accordance with the task set.

3. Post-computer work. It is the period of work during the lesson when students are supposed to report in some form on the results achieved by them when working on the Internet.

As it can be seen from above, for in-class work on the Internet Barrett and Sharma mostly recommend students' Internet research, thus implicitly endorsing our assumption that such research is the principal form of using the Internet in language teaching and learning. But the authors also suggest other possible on-line uses of Internet technologies in ESP/Business English classes (Barrett, \& Sharma, 2003: 38):

- students may use web-sites as parts of presentations delivered by them in class:

- the same can be used by the teacher (s/he may use a web-site as part of his/her presentation);

- students may collaborate when doing some learning project in class via the Internet. Barrett and Sharma $(2003,38)$ give the example of creating students' own website as a learning project.

Two kinds of on-line Internet work distinguished by Barrett and Sharma (2003: 38) are organized not directly in class but immediately precede or immediately follow the lessons. They include:

- learners doing a task on a web-site just before their arrival for a lesson (pre-lesson task);

- learners following the lessons with some task done on a web-site (postlesson task). 
Off-line use of the Internet facilities, according to Barrett and Sharma (2003: 38), embrace all cases when students work on the Internet out-of-class with the aim of using the results of their Internet search (the materials taken from websites) during the following lessons. For instance, such materials can be used as a stimulus for in-class discussion, or as the informational foundation for students presentation, or as information relevant in doing project assignments, etc.

Both the on-line and off-line organizational forms are possible and necessary to be used in ESP courses at tertiary schools. A third organizational form that was not accounted for by Barrett and Sharma is also possible. It is implemented through students working on the Internet mostly in their classroom - doing the Internet search in accordance with the task(s) given by the teacher (pre-computer and computer work in the on-line alternative suggested by Barrett and Sharma). After that, the material found during the search is processed out of class and the results are reported in one of the following classes, for instance, when students make presentations summarizing their findings on the web. In this case, the post computer work of Barrett and Sharma is organized following the off-line pattern. This creates the third, mixed, on-line-off-line organizational structure of using the internet for teaching ESP.

This was our primary organizational structure when developing the constructivist blended learning approach because it has a number of advantages specifically for the conditions of ESP teaching at tertiary schools:

1. It solves all possible problems with students having difficulties in accessing the Internet out of class. Universities nowadays are mostly sufficiently provided with Internet facilities to organize students' computer work in the classroom. But in some countries (like Ukraine) not all students have Internet connections at home. So, making them do frequent (more often than once in one or two weeks) Internet search assignments out of class would mean for them the necessity of frequently visiting Internet cafes and paying for using the facilities there. It is not always ethical to make students incur such additional expenses too often. As to doing the Internet search assignments in universities' computer laboratories during after-class hours, this is not the best solution for all cases either because computer laboratories/classes are regularly overcrowded at some universities so that a student may need to wait a couple of days to find a place to work there. Therefore, only computer work during lessons can ensure that all students do their mandatory and most important for the learning process Internet search assignments in time and without organizational problems.

2. Students are not always competent and proficient enough in doing their Internet search and working with information sources from the Internet, especially if those sources are in English. When their Internet search is teacher-supervised, such problems disappear because students can al- 
ways turn to their teacher for help. This approach can also accelerate students' Internet proficiency development (especially in what concerns working with Internet sites in English).

3. The suggested organizational form enables students' groups engaged in computer/Internet assisted ESP learning to occupy computer classes/laboratories with Internet connection only for what they are really needed - for working on the Internet. Students come to a computer class/laboratory, get instructions from their teacher, and work on the Internet all through the class period (pre-computer and computer work according to Barrett and Sharma - see above). Post-computer work is done in traditional classrooms, not in computer ones as it follows from Barrett and Sharma's scheme of on-line lessons. That makes using computer classes/laboratories much more economical and cost-effective because working in computer classrooms without using computers is totally avoided.

4. If blended learning is combined with the constructivist approach to ESP teaching/learning (as it is advocated in this monograph - see the Introduction), the Internet research done by students becomes regular and mandatory. Making some learning activity regular and mandatory requires considerable organizational efforts, especially at the early stages of introducing that activity. This is why at early stages in a constructivist ESP course it is better to organize the most important students' Internet search activities in class and under teacher's direct supervision.

It was due to the reasons listed above that in our ESP course for future psychologists embodied in the coursebook Psychological Matters (Tarnopolsky, Kozhushko, et al., 2011a) special Internet search classes were introduced into the course and coursebook structures. Every Internet search class is a two academic hour class period held in one of university's computer classes/laboratories and totally devoted to students' mandatory Internet search (pre-computer and computer work) done under the teacher's supervision. The search is done to collect materials for doing some creative learning assignment with the results to be reported during one of the following class periods held in a traditional classroom but not in a computer one (post-computer work).

Such Internet search classes are held approximately once every three weeks as every sixth or seventh class period in the framework of the entire ESP course. The two academic hour-long Internet search class period (eighty minutes which make two academic hours by Ukrainian standards) is divided into two equal parts with 40 minutes allocated for each of the parts. Each of the two parts is numbered: Internet search 1 and Internet search 2.

An example of Internet search 2 assignment has already been demonstrated in section 2.3 .1 of Chapter 1 devoted to students' project work. In the coursebook Psychological Matters all Internet search 2 assignments are designed in quite a 
similar manner because all of them are aimed at students collecting the materials for preparing separate parts of their Short Psychological Encyclopedia - a through project that learners work on during all the period of their studying an ESP course for psychologists (c.f. 2.3.1 in Chapter 1).

Unlike Internet search 2, Internet search 1 assignments are more short-termed tasks aimed only at one professional theme under discussion within the boundaries of just one unit of the coursebook (not aimed at something as general and embracing the entire course as A Short Psychological Encyclopedia). The results of Internet search 1 are supposed to be reported by students not later than the next class period. Three examples of Internet search 1 assignments are given below to demonstrate the variety of creative experiential learning tasks that learners may do on the basis of the information obtained in their Internet search. The first is taken from Unit 7 of the coursebook Psychological Matters - Personality and Individual Differences.

Internet search 1. As you most probably know, the important parameters of people's personality are:

- Extraversion/Introversion (whether a person is talkative, sociable, and socially self-confident or the opposite of that):

- Agreeableness (whether a person is cheerful, warm, and empathic or unsympathetic and grumpy);

- Openness to experience (whether a person is curious, imaginative, and artistic or practical and focused);

- "Natural Reactions» (whether a person is calm and contented or easily upset, tense, and anxious):

- Conscientiousness (whether a person is hard working, self-disciplined and well-organized or disorganized, easily distracted, and unreliable).

Now, working in the Internet class, do an Internet search using the web sites that your teacher recommends and some other sites that you will be able to find.

First, divide into five small groups (from two to three students in every group). Second, every group should choose one of five personality parameters. For instance, the first group can choose Extraversion/Introversion, the second Agreeableness, the third Openness to experience, etc. You are required to choose only one parameter and inform your teacher which one it is going to be, so that all groups have different parameters to work on.

Now your task is to search on the site or sites recommended to you or the ones that you have found yourselves for information about the personality parameter that you are studying. You should find both general information and practical itlustrative information (for instance, information about behavior and problems of certain people who are introverted, or are not open to experience, or are easily upset, tense and anxious - case studies).

On the basis of the information found, prepare a presentation of about fiveminute duration on the personality parameter that you have studied. In the next 
class, you will have to deliver your presentation to all the other students who will then discuss it. Decide what each partner from your small group will present.

You have 40 minutes to do the assignment.

The second example is taken from Unit 8 of the coursebook Psychological Matters with the topic Psychotherapy.

Internet search 1. Working on the Internet class, do an Internet search using the web sites that your teacher recommends and some other sites that you will be able to find.

Divide into groups of four students. Every group should find and read on the Internet one case study of psychotherapeutic problems. You are required to inform your teacher what particular case your group is going to study, so that all the groups have different ones. On the basis of the information found, prepare "a seminar of psychotherapists" for the next class. During the 15-minute seminar that each small group is going to conduct in the next class, two students from that group will present the case: they will speak about the client's problem(s) and complaint(s) that s/he came with to the therapist. They will also discuss what real underlying causes of the problem(s) and complaint(s) were revealed during the first psychotherapeutic sessions. After that, the third student from the small group will ask the opinions of "colleagues" (all the other students from the class who are taking part in the "seminar") as to how the problem(s) should be dealt with (what the psychotherapist should do during the following sessions to help that particular client). When all the ideas are collected, the fourth presenter should inform what the course taken by the psychotherapist who described the case on the internet site really was. The 15-minute seminar should finish with the discussion of the relative merits and demerits of the courses of treatment suggested by "the participants of the seminar" (students) and the psychotherapist who was actually dealing with the case.

You have 40 minutes to do the assignment.

The last example is taken from Unit 9 of the coursebook Psychological Matters. The name of the unit is Gestalt Therapy.

Internet search 1. Working in the Internet class, do an Internet search using the web sites that your teacher recommends and some other sites that you will be able to find.

Divide into pairs. Every pair should choose one or two of Gestalt techniques or one or two of Gestalt exercises. Do not limit yourselves to those techniques and exercises that you have already read about or discussed. You can and should find some other kinds of them in the Internet (for instance, the awareness continuum in a meditative context exercise). You are required to inform your teacher which kind of techniques or exercises your pair is going to work on, so that all pairs have different ones.

Now your task is to search on the site or sites recommended to you or the ones that you have found yourselves for information on psychotherapeutic sessions where such techniques or exercises are used. The best option would be to find particular cases and transcripts of sessions that can serve as examples. 
On the basis of the information found, prepare a role-play of about three-minute duration in which you will model a part of a (Gestalt) psychotherapeutic session. During the session, the technique or exercise that you found in the Internet has to be demonstrated. So, you have to invent the case of a client (one student in the pair) that would make appropriate the use of such a technique or exercise by a psychotherapist (the other student in the pair). In the next class, after demonstrating your 5-minute role-play, you will both have to make a 3-minute presentation where you will need to give the reasons for choosing just that technique or exercise for the particular case given and discuss what was expected to be achieved (search for the reasons for using each particular technique or exercise on the Internet as well). You should also be ready to answer the questions from the other students and the teacher concerning the technique or exercise that you were demonstrating in your role-play and concerning the appropriateness of its use.

Discussing in your pair the materials found during the Internet search, decide what role each partner will play in your role-play and prepare a draft of it la draft script). You should also prepare the plan of your short presentation after the roleplay and decide what each partner will say during the presentation.

You have 40 minutes to do the assignment.

The examples above demonstrate that students' Internet searches can and should be organized to do productive, creative, and experiential tasks on the basis of their results, so that speech reception - while reading (or listening to) professional information on Internet sites - leads to speech production like preparing and delivering presentations, conducting seminars, role playing, etc. The speech production in this case is not limited to speaking; writing is involved as well. First, to prepare a presentation (see the first example), students need to write its notes; to conduct a seminar like it is required in the second example, the description of a particular case needs to be written, etc. Second, the task connected with the Internet search may be directly focused on writing - like writing an essay, a report, or an abstract on the basis of the information found (c.f. also Weissberg, 2009).

Another peculiarity of the given examples that deserves attention is the fact that all three of them involve students doing their Internet search in pairs or small groups. Though this is absolutely optional and students can do the Internet search individually (and should quite often do so to develop their learning independence), collaborative Internet research has some considerable advantages:

- students communicate in English with each other which is helpful in developing their speaking skills (it is the supervising teacher's duty to block any attempts to use learners' L1 in the process of their collaborative Internet search);

- students with better competence in using the Internet can help and teach the students whose proficiency in that respect is at a lower level;

- if the computer class/laboratory with the Internet connection where the students are working has fewer computers than the number of students in the group, collaborative Internet search solves the problem. 
The third peculiarity which is most clearly observable in the second example above is the help that the Internet research can render in developing students' critical thinking - in Freire's (1973) understanding of the term - in their language studies. Discussing and critically evaluating during the modeled "seminar of psychotherapists" the professional information found on the Internet is a very good way of developing critical thinking through the medium of the target language. Though in principle all experiential learning activities are propitious for critical thinking development, as follows from their description in Chapter 1, the Internet research tasks place such development on a much more regular basis thanks to supplying students with numerous materials on which to practice their critical thinking skills. Therefore, such tasks are of great importance in forming and improving those skills whose development is considered to be one of the priorities in contemporary language teaching (Kabilan, 2000; Mitsaki, 2012).

The fourth and last peculiarity of the given examples to be discussed is the fact that in each of the examples (instructions for learners) it is indicated that the teacher is supposed to provide students with the addresses of some sites where to do their Internet research. An important issue is where the teacher is supposed to take those sites. This question is answered in the Introduction to the Teacher's Book attached to the coursebook Psychological Matters. The quotation below from the aforesaid Teacher's Book explains that:

"To organize students' Internet searches, the teacher has to be able to recommend different professional web sites in English to his/her students. For this purpose, s/he is required to collect and constantly renew his/her Library of psychological sites in English. The authors of the coursebook could not provide the teacher with such a Library of sites because the sites themselves and the information in them frequently change. Of course, beginning to collect his/her Library of sites, the teacher should better use as a starting point those web sites that are indicated in the Student's Book and Workbook as sources of the texts for reading. Some of those sites may lead him/her to other sites and in this way help to create the entire Library. But the teacher should keep in mind that, first, the Library of sites has to be collected before the work with the coursebook begins in the classroom (the teacher is going to need his/her Library from the very first class on Unit 1) and, second, the teacher has to check the collected sites at least once in two months to be able to replace the sites that have become obsolete or disappeared." (Tarnopolsky, Kozhushko, et al., 2011b: 12).

This recommendation is valid for every kind of ESP course based on whatever students' majoring disciplines if learners' Internet search is planned to be introduced as a regular and mandatory learning activity. In this case, the teacher should always be able to recommend a number of Internet sites in English to his or her students (especially if students' Internet search is conducted in the classroom), both upon request and when giving them assignments on doing that search. This is possible only if s/he is in possession of a well-stocked, con- 
stantly replenished and renewed library of such sites adapted to all the possible needs of the teaching/learning process. On the other hand, the teacher is supposed to teach the students how to find relevant sites in English on their own, i.e., how to best use search engines to become independent in their Internet research learning activities (and in later professional activities when doing Internet research for professional purposes on professional Internet sites in English).

Everything said above about learners' Internet research in their ESP classroom does not mean that out-of-class (off-line in the terminology of Barrett and Sharma, 2003) Internet research is meant to be totally excluded. Out-of-class students' work on the Internet is receiving increasing attention in language teaching today (Symposium on language learning beyond the classroom, 2012) and can by no means be disregarded. The approach that is suggested in this monograph envisages quite broad and regular use of students' off-line activities. That can be shown by examples of learning tasks (home assignments) taken from the coursebook Psychological Matters (Tarnopolsky, Kozhushko, et al., 2011a). Three such home assignments are quoted below:

1. Divide the class in two groups. The students from the first group (group A) have to read the text in activity 6 from Unit 2, Step 1 in the Workbook. This short text is devoted to the behaviorist Edward Lee Thorndike. The students who are going to read the text should get ready to be interviewed about the life and work of Edward Lee Thorndike (find additional information about him on the Internet using the site or sites recommended by your teacher). The students from the second group (group B) have to read the text in activity 7 from Unit 2, Step 1 in the Workbook. This short text is devoted to the behaviorist Clark Hull. The students who are going to read the text should get ready to be interviewed about the life and work of Clark Hull (find additional information about him on the Internet using the site or sites recommended by your teacher) (Unit 1. Psychology and its Branches).

2. Prepare a presentation in pairs on the basis of text 1 from Unit 8, Lead-in in the Workbook. That text discusses nine different approaches, or branches, in psychotherapy. Your teacher will now tell you what approach, or branch (it may be two approaches or branches), every pair will be discussing in their presentation. The pairs will have to give a 5-minute presentation on those approach(es) or branch(es). For preparing the presentation, use not only the text from the Workbook (there is too little information on each approach or branch, in it). Find additional information on the Internet, using the sites recommended by your teacher. (Unit 8 . Psychotherapy).

3. Divide into small groups of 3-4 students in each of the groups. On the basis of text 1 from Unit 10, Lead-in in the Workbook (see the assignment above), and also on the basis of what you were reading and discussing in this class, prepare 
in your small group a 10-minute presentation under the title What Psychological Counseling Is, What it Isn't, How and in What Cases It Can Help People (the time for every presentation includes the time for possible additional questions from other students and the teacher when the presentation is over). For preparing the presentation, use not only the text from the Workbook and the materials from the Lead-in in the Student's Book. Find additional information on the Internet, using the sites recommended by your teacher. Also keep in mind that a Contest of Presentations is going to be held in the next class and one presentation (and the small group who prepared it) will be proclaimed the winner of the Contest (Unit 10. Psychological Counseling).

As it can be seen, off-line students' Internet research can also be mandatory and indicated as such in assignments included in the coursebook. It should be so to provide optimal conditions for blended learning because in-class Internet search done, as it is suggested above, only once in three weeks is hardly sufficient. (In-class Internet search cannot be made more frequent since most of the class time should be devoted to natural, and not virtual, communication in the target language.) Therefore, students should get additional off-line Internet search assignments at least once in two weeks - once a week if possible. On the other hand, such assignments can hardly be made more frequent not to overload learners, especially in conditions as those mentioned before, when finding Internet access outside the university can pose financial problems for some students.

Since, as indicated in section 1 of this chapter, Internet search is only one of the possible ways of using Internet technologies for EFL/ESP teaching and learning, it is now necessary to discuss what place other ways can occupy in the organizational structure of introducing the Internet into ESP courses.

In general, all the possible ways of using Internet technologies for teaching ESP should be divided into two categories: the principal (mandatory) ways and the optional ones.

Since the structure and the process of teaching and learning every ESP course depends on the coursebook that is chosen for that course, the principal (mandatory) ways can only be those that the author(s) of the coursebook can regularly utilize for designing learning assignments that are included into the coursebook and that students are supposed to do by all means.

It is clear that only Internet research assignments can be listed as mandatory Internet-based activities of this kind because nowadays hardly any tertiary school may be found that is unable to organize sufficiently regular on-line Internet search classes for their students. Even off-line Internet research, if it is not too frequent (see above), can be safely made mandatory, at least for most universities. This is why Barrett and Sharma, often quoted in this chapter, aimed at on-line and off-line students' Internet search, and at practically nothing else, 
the organizational structure developed by them - that of using the Internet for teaching ESP/Business English (Barrett, \& Sharma, 2003: 38).

On the other hand, all the other Internet-based ESP learning activities should better be included into the category of optional ones, and whether to utilize them or not should be decided by the teacher depending on local conditions, particular curriculum and a lot of other factors.

For instance, using computer ESL/EFL teaching programs that were discussed in section 1 of this chapter - and first of all, the programs on the Internet because they are often renewed and modernized - is very desirable and can greatly help in accelerating the development of learners' communication and language skills. But utilizing such programs cannot be made mandatory and indicated as such in the coursebook for whatever ESP course. First, this is because every particular program indicated there can disappear from the Web during the period the coursebook is being used (or from the market if it is a stationary program on CDs). Second, using such programs is not free and it is hardly ethical to include payable learning activities into a coursebook as mandatory ones. So, a coursebook author can only recommend using computer/ Internet programs as optional learning activities citing some relevant programs that may be used while they can still be found on the Web or on the market.

The same concerns communication via the Internet, such as e-mail, chat rooms, forums, etc., and also doing Internet projects with other students - including students from other universities and even other countries. Those activities are also more than desirable to be involved in a constructivist blended learning ESP course. Giving students tasks via the Internet and receiving their completed tasks in the same way; receiving consultations, prompts and assessments from the teacher electronically; participating in forums and chat rooms in English on the issues connected with learners majoring disciplines; doing via the Internet joint learning projects with students from different universities and different countries; communicating via e-mail with students who have identical majoring disciplines to learn but who are native speakers of English - all such activities raise the process of ESP teaching and learning onto a much higher level. This is why, when there are opportunities for using those activities, they should be used by all means. But whether those opportunities do exist, can be decided only locally; this is why the activities in question cannot be introduced into an ESP course as mandatory ones by a coursebook writer or a compiler of a sample curriculum, though recommendations in that respect should be given.

Some words should be said separately about using e-mail correspondence in ESP courses. The skills connected with such correspondence in English are very important nowadays for a specialist in every field. This is why even special coursebooks are published for teaching emailing in English (c.f., for instance, Emmerson, 2004). So, if there is an opportunity of using emailing in English in ESP courses (and that opportunity exists quite often), it should be used in 
a mandatory manner. But first, that mandatory nature of e-mail use cannot be regulated by a coursebook or even a curriculum/syllabus. It is for the teacher to decide where and how to utilize it depending on the particular conditions in which s/he and his/her students are working in every particular academic environment. Second, ESP courses are not designed for teaching students emailing in English. Being one of the fundamental survival skills nowadays, emailing should be taught in preceding courses of General English. Therefore, in our case, emailing is included in the list of optional learning activities for an ESP course.

Finally, the last form of using the Internet in EFL/ESP teaching mentioned in section 1 of this chapter was publishing students' written works on the Web. This activity, just like emailing, is also practically mandatory if the university has its own website and different web-pages on it (which is unavoidably so now). Besides, there is always an alternative of students' creating their own website or a web-page for publishing their works. But from the point of view of designing an ESP curriculum, syllabus, course, or of writing an ESP coursebook, this activity can only be optional, though strongly recommended to the teacher, because it is only on the decisions of the latter that the time, place, and choice of students' works to be placed on the Web can depend.

It should also be noted that if students have access to computers (and this is practically a universal situation now), they should be requested to do all their written works on computers only and not hand them in handwritten. That must be done to inure learners to using all the advantages of the text processor discussed in section 1 of this chapter.

Everything said in this section about the organizational structure of using the Internet for teaching ESP at tertiary schools can lead to the conclusion that such a structure should presuppose the inclusion of students' Internet research as an absolutely mandatory learning activity into an ESP coursebook and ESP course as a whole, the relevant activities being done both on-line and off-line. All the other ways of using computer/Internet technologies can be regarded only as optional, though as highly desirable ones, and their use should depend on local conditions and the teacher's judgment.

Having decided that, it is important to explain how Internet research can help in implementing the constructivist approach, namely, its two principal constituents: the experiential interactive teaching/learning and the contentbased instruction. This is the subject matter of the two following sections in this chapter. 


\section{Internet research as a means of implementing experiential interactive teaching/learning}

Beginning the discussion of this issue, it should be noted that conducting Internet research on Internet sites in English by itself ensures the intensification of development of learners' English reading skills. If such sites include audio and video materials (which is a very frequent case now), the intensification involves the development of listening skills as well. This is quite understandable and does not require additional explanations since intensification happens simply because of expanding learners' communication practice in those two kinds of receptive communication activities. Due to the same cause, students' lexical and grammatical language skills will also develop in a more intensified manner. That especially concerns receptive lexical and grammatical skills for reading and listening but those skills can easily become more productive and start serving speaking and writing if vocabulary and grammar initially acquired through reading and listening begin to be actively used in speech production when learning tasks require such using.

It should also be noted that in students' Internet research, the information search activities characteristic of a future specialist's (in whatever field) professional work are faithfully modeled. As a result, when students' Internet research is being done in the process of ESP learning, the principal advantage of experiential teaching/learning is ensured: subconscious acquisition of target language communication and language skills in an extra-linguistic activity modeling professional activities and aimed at solving professionally oriented learning tasks. This is the reason why in Chapter 1 Internet research was included into the list of experiential learning activities.

The same applies to using Internet research for acquiring target language writing skills. For instance, if such research is done with the purpose of obtaining certain data required for writing an academic essay or with the purpose of obtaining some materials required for reporting in writing on the learning project's intermediate results, that research does not just supply information or provide ideas for the essay or report in question. It also supplies samples of written professional communication in the target language - the samples illustrating the peculiarities of style and formatting, lexical and grammatical peculiarities, ways of expressing one's ideas when writing on professional issues in the target language, etc. Such samples are meant to be attentively studied and followed when students are writing their own works.

Internet research also plays a significant role in developing students' speaking skills. But discussing that requires special analysis of Internet research's impact on all those experiential learning activities that were under consideration in Chapter 1. Such an analysis is also required to understand in greater detail Internet's influence on the development of all the other communication and language skills. 


\subsection{Internet research in organizing role plays and simulations}

In this case, like in all the others, Internet research plays its principal role - that of supplying information and samples for students' speaking.

For instance, if students of Economics and Business are expected to simulate some kind of business negotiations, they may be requested to find on the Internet several samples of business talks in English, represented both as graphic texts and as recorded ones (e.g., YouTube) to provide them with the examples to follow in their own speaking. If students of Psychology are given the task of role playing a certain type of psychological session, finding recorded samples of several such sessions on the Internet would be a rational first step so that students have better ideas how it is done, what lexical, grammatical, stylistic and other peculiarities of oral communication are characteristic of such sessions, etc. Using samples like those ones allows learners to make their own role plays and simulations more creative and complicated. For instance, in the first of them, staged immediately after studying the samples, students may only model those samples, more or less faithfully imitating what they have heard and/or read on the Internet with just minor changes in the situations, characters involved, etc. But gradually those changes may become greater with increasing distancing of students' speech production from the original samples, so that, finally, the original samples become barely recognizable in learners' communication.

Another alternative that may be suggested is similar as to organization but more difficult for students (therefore, meant for somewhat more advanced stages in the ESP course). Learners are requested to find on the Internet not a sample of business talks or a psychological session but their descriptions in full-size texts, for instance, a description of a particular case of business negotiations or particular cases of psychological sessions (like the description of a particular client's case with indicating the ways of treating the psychological problem that were recommended in the course of some psychological sessions). Students are required to stage a role play or a simulation on the basis of the descriptive materials that they have obtained. It means, for example, staging a session where the particular case was discussed and particular recommendations arrived at or staging business talks with particular data concerning their progress and decisions taken from the description read on the Internet, etc. An example of this alternative was given above in section 2 of this chapter in the task where students were required to do Internet search for organizing "a seminar of psychotherapists" (see the second example among three examples of Internet search 1 assignments).

The third alternative is even more difficult for students requiring greater efforts and greater involvement of their creativity and imagination for staging a role play or a simulation (still more advanced learning stage). The tasks of this kind abound in the coursebook Psychological Matters (Tarnopolsky, Kozhushko, et al., 2011a). 
The essence of every such task is to make students find on the Internet a case representing a certain psychological problem - for instance, a typical case of a job burnout. On the basis of the symptoms of the case, the learners are requested to stage a role play simulating a psychological session with a client suffering from job burnout with the symptoms like those found on the Internet site. As a result of the session, psychological recommendations are arrived at.

The most sophisticated, creative, and difficult for students is the fourth alternative when learners find on the Internet only the generalized information. On the basis of it, they have to invent and stage on their own a role play or a simulation. For instance, it may be a generalizing text on how to conduct business talks or a psychoanalytic session. Using that general information, students themselves invent a particular case requiring business negotiations or a particular client's case with a particular psychological problem to be solved that requires a specific session of psychoanalysis. Then, the business talks on the invented issue or a psychoanalytic session on the invented case are simulated/role played following the generalized guidelines found during the Internet research. Naturally, this alternative is for later, maybe even final, stages of an ESP course. Actually, this is the case of learners' creating their own role plays - an approach becoming popular in today's EFL teaching (Schaefer, 2012).

In all the four alternatives, the Internet research creates the informational and linguistic basis for students' speaking while they are role playing or doing their simulations. Besides, by its very nature that research contributes to developing learners' reading and listening skills. It also contributes to developing their writing skills, first, due to learners having a need of taking written notes in the process of Internet research for further organizing their role plays/simulations and, second, because such role plays/simulations can have specific writing assignments as their end-pieces (c.f. Chapter 1, 2.1.1, 2.2.1). In this way, the favorable effect of Internet research spreads to the development of skills in all kinds of communicative activities (reading, listening, speaking, and writing) when students are engaged in such experiential learning activities as role plays and simulations. This favorable effect also embraces the development of language skills because it is from their Internet-researched materials that students gain a considerable part of the vocabulary and grammar to be used by them in role plays and simulations.

What was said in the paragraph above concerns all the other experiential learning activities mostly focused on speaking and discussed below, so it will not be mentioned again.

\subsection{Internet research in organizing project work}

As already said in Chapter 1, project work is one of the most important experiential learning activities required for adequate implementation of the 
constructivist approach to ESP teaching and learning. This is because no other experiential learning activity can unite so organically all the four basic types of communication activities: speaking, reading, listening, and writing, creating the best conditions for joint development of all relevant skills (c.f. Chapter 1, 2.3). What is no less important is the fact that no other experiential learning activity can ensure such a high level of learning autonomy and learners' creativity by way of most faithfully modeling future professional search and research activities (c.f. Chapter 1, 2.2.3. 2.3). But it should be emphasized that in ESP courses efficient project work is very difficult, to say the least, if it is not based on Internet research done on professional sites in English.

To illustrate this, it is worth giving an example of one Internet search task (Internet search 2 - c.f. section 2 in this chapter) connected with the project work aimed at creating students Short Psychological Encyclopedia (c.f. 2.3 in Chapter 1) in the ESP course for students majoring in practical psychology. The example is taken from Unit 2 - History of Psychology - of the coursebook Psychological Matters (Tarnopolsky, Kozhushko, et al., 2011a).

Internet search 2. Project work. Here is the second task for preparing one more chapter for your SHORT PSYCHOLOGICAL ENCYCLOPEDIA. This second chapter planned for the Encyclopedia is to be devoted to The History of Psychology in the $20^{\text {th }}-21^{\text {st }}$ Centuries.

Now you are going to do your second Internet search in this class period. Use the web sites that your teacher recommends and some other sites that you will be able to find.

You should search for any information on the history of psychology in the $20^{\text {th }}$ early $21^{\text {st }}$ centuries that you can find and that can be considered as generalizing all the most important psychological theories and approaches developed in those centuries. You are required to inform your teacher what information you are going to work on so that different students have different information sources and collect different information.

After your source (sources) is chosen, start collecting information from the Internet. Your goal is to prepare a 5-minute generalizing oral presentation on the history of psychology in the $20^{\text {th }}$-early $21^{\text {st }}$ centuries and on all the most important psychological theories and approaches developed in those centuries. You will also have to prepare a short article on that issue for the Encyclopedia. All this will have to be delivered in the next class. Your short article is supposed to be of about 150 words. Keep in mind that you will be requested to hand in your article for the Encyclopedia in the electronic format.

You have time until the end of the class to do the assignment.

To do this project task is practically impossible without an Internet search. In most cases, students will simply not be able to find enough printed sources to collect all the required information. Similarly, the teacher will not be able to provide them with sufficient variety of printed sources so that every student in the 
group can find information differing in some respects from the information found by all the other students so that every one of them can include in their presentation some data unknown to other learners. But these tasks can be solved without great problems if the Internet is chosen as the source of information.

Therefore, the principal form of using Internet research in project work is students' selection from the Internet of all the subject matter materials required for completing their project tasks. It should also be mentioned that if for preparing every particular role play and simulation students mostly need to do their Internet search only once (c.f. section 3.1 above), for every particular project task the Internet search needs to be done a number of times - at least once for every stage of the project. It may be said that project work always requires doing multiple Internet research.

It should be noted as well that such a form as publishing learners' written works on the Web is most suitable for using in the framework of students' project work. It has already been said in Chapter 1 that there must be some material product as the outcome of that work. That product is most frequently something written by the students - like, for instance, a written or, better, printed review of the principal trends and theories in the development of Psychology as a science during the $20^{\text {th }}$-early $21^{\text {st }}$ centuries (see above). If the material product has the features of a genuine publication (and every publication on the website is a genuine publication), students' learning motivation when doing project work is greatly enhanced since they perceive that work as real research activities in their future professional field with the results of those activities accessible to and subject to evaluation by other people - first of all, the specialists from that professional field. This increases the sense of competence, and with that learners' self-esteem (Arnold, 2012). The motivation enhancement is inevitable in such a case, as well as the enhancement of responsibility for the results of one's own work that may be evaluated by specialists. It raises students' efficiency in what they are doing, therefore, positively influencing the development of their target communication and language skills.

\subsection{Internet research in organizing brainstorming, case studies, and discussions}

Just like in Chapter 1, these three kinds of experiential learning activities are best analyzed together due to their similarities and their trend to continue each other in the teaching/learning process: case studies following brainstorming and discussions following case studies (c.f. 2.4.1-2.4.3 in Chapter 1).

It should be remarked that for all the kinds of learning activities under consideration the main purpose of Internet research is to find issues to be talked over and the outlines of solutions for such issues. 
For instance, students may receive an Internet research assignment from their teacher requesting them to find some issues in their field of knowledge that are topical for all specialists in that field at the moment but have not yet been finally and adequately solved. The issues found and suggested for discussing by different students are talked over in class with the aim of deciding which of them may be chosen for further analysis (or with the aim of deciding on the sequence of analyzing all the selected issues). When the issue for analysis has been chosen, students are divided into small groups of three-four learners in each of them to brainstorm it. Having collected "a bank of ideas", the students get the task of finding specific cases on the Internet illustrating the problem under discussion, so that such cases could be used for case studying. The cases are discussed in the same small groups, and finally, a whole-class discussion is organized when all small groups make their conclusions known to the other students in class. The class is expected to discuss the conclusions of every small group, so as to come to a consensus in what concerns the best solution of the issue/problem under consideration. At this stage, returning to Internet research is quite reasonable. It may be for either finding confirmation of the ideas formulated in the whole-class discussion or, vice versa, for understanding why those ideas were wrong and what better solutions are possible.

With such an approach as suggested above the sequence of brainstorming $\rightarrow$ case studies $\rightarrow$ discussions recommended in Chapter 1 (2.4.3) is brought to life. But Internet research can be used in an identical manner to organize each of those three learning activities separately from the two others without passing from one of them to any other one as a follow-up.

For instance, students can get the task of finding on the Web cases of some professional problems where certain solutions are recommended. After that, the class is divided into small groups and every student presents in the small group the case found by him/her without telling the other students about the solution recommended on the Internet site. The case is analyzed by the small group until some solution is arrived at (the student who presented the case does not participate in the analysis). After the solution has been reached, the presenter of the case lets other students know what the solution suggested on the website was and the small group discusses the relative merits and demerits of both solutions - theirs and the one suggested on the website. After that, another case found by some other student in the small group is discussed and so on until all the selected cases have been analyzed. It may be remarked that such kinds of tasks and a number of others similar to them in essence (c.f., for instance, Chazal de, 2012) are very good for developing students' critical thinking through the medium of the target language.

A similar approach may be followed when organizing brainstorming or discussions separately from the two other kindred types of learning activities.

Certainly, some other, alternative, ways of introducing Internet research into the process of organizing such experiential learning activities as brainstorming, case studies, and discussions can be found. 


\subsection{Internet research in organizing students' presentations}

In what concerns Internet research for organizing students' presentations, practically the same may be said on this issue as when discussing its use for organizing project work. It would be practically impossible for students to collect enough authentic professional materials for an adequate presentation on some professional issue if Internet is not made recourse to as the source of information. In a university outside English-speaking countries in many cases it will be well-nigh impossible to find enough printed materials in English that would suit all the requirements as to professional authenticity, variety, up-to-datedness, and sufficiency. Thus, in this case, the same arguments are valid as were given when discussing the importance of Internet research for project work activities. The principal difference is the already mentioned fact that in project work the Internet research is multiple whereas, when preparing every particular presentation, it is mostly done only once (though there are cases when there emerges a necessity to repeat the Internet search and find some additional materials for the presentation when the bulk of such materials for it has already been collected).

One more aspect should be taken into account. Nowadays, a presentation is not considered to be adequate if it is not accompanied by illustrations in PowerPoint. Therefore, when teaching students presentations in English, they have to be requested to prepare PowerPoint illustrations for every presentation of theirs. A greater part of such visual illustrations needs to be prepared by students themselves: tables, schemes, summaries of the main points made in the presentation, etc. But some of them can and should be taken from the Internet and students may be instructed to do so as it is done in one of the assignments taken from Unit 1-Psychology and Its Branches from the coursebook Psychological Matters by Tarnopolsky, Kozhushko, et al. (2011a):

Internet search 1. Working in the Internet class, do some Internet search using the web sites that your teacher recommends and some other sites that you will be able to find.

The class is divided into pairs. Every pair searches for information on one of the branches of Psychology that were mentioned in the text for listening in this Unit but were not analyzed in details as the four branches that you were reading about in the preceding class had been. Every pair is supposed to choose one of the following branches for collecting some information about it: Biopsychology, Forensic Psychology, Social Psychology, Personality Psychology, Developmental Psychology, or School Psychology. You are required to choose only one branch and inform your teacher which one it is going to be, so that all pairs have different branches to work on.

After your branch is chosen, start collecting information about it from the Internet. Your goal is to prepare a 5-minute presentation on that branch for the next class. 
In your presentation you should speak about the field of research and practical activities of psychologists working in the branch that you have chosen, the history of its development, the famous psychologists working in that field, the significance of the field for modern psychology. Find illustrative material on the internet to be used during your presentation: practical examples, pictures illustrating the work of specialists, portraits of famous psychologists representing the field, etc. Discussing in you pair the materials found during the search, decide what each partner from the pair will present. You have 40 minutes to do the assignment.

It should also be remarked that the presentation results, just like project work results, can be placed on web-sites. The quality of presentations delivered by students reflects the development of their ESP language and communication skills to no lesser degree than the quality of their project tasks results. Just like in the latter case, the development of skills in target language reading, speaking, listening, and writing is demonstrated in the unity of all those skills. This is because preparing a presentation requires reading of relevant materials and, in many cases, listening as well, if the materials are collected on the Internet. After that, preparing a presentation passes through the stage of writing (writing notes or the full text of the presentation which can later be placed on the web-site). Finally, presenting itself is totally based on oral communication. In this way, every student's presentation accurately reflects on what level that particular learner is able to communicate in the target language. Therefore, placing the texts of the best students' presentations on web-sites can have a considerable motivating impact. First, students can regard that as the recognition of their sufficiently high level of target language command. Since, in principle, everyone, including native speakers, can read learners' works on the Web, if they are placed there, it implicitly means that the language in them is quite adequate. Second, students can also regard that as the recognition of high quality content level in their presentations because, being accessible to everybody, including specialists, their placement on the Web implicitly means that the text of such presentations may be of some interest to specialists. This means the recognition of learners' professional competence, such recognition naturally enhancing their self-esteem (Arnold, 2012).

\subsection{Internet research as a means of ensuring interactivity in experiential interactive teaching/learning}

Having discussed the means of using Internet research for optimizing the experiential learning activities, it is also worthwhile to analyze how such research can help in providing for the interactive nature of experiential ESP teaching/learning process. 
It has already been indicated that, according to Barrett and Sharma (2003: $35)$, working on the Internet is always interactive by its very nature. But only this feature does not limit the significance of Internet in ensuring the interactivity in a constructivist ESP course. Of no lesser significance is the fact that a number of authors, including many times quoted Barrett and Sharma (2003), recommend that Internet research is organized in pairs or even small groups of three or four students. This is characteristic of Internet research assignments used in the approach advocated in this monograph, as can be seen from the examples given earlier. One of the important benefits, among others (c.f. section 2 in this chapter), is making students speak English among themselves when doing Internet research together.

Finally, probably the most important feature of the Internet that makes it an irreplaceable tool for ensuring the interactivity in ESP teaching/learning is the fact that hardly anything else can provide the same level of interaction with outside professional target language environment/outside professional target language sources of information (c.f. section 4 in Chapter 1). It is practically only via the Internet that students studying ESP at a university outside an Englishspeaking country can get access to that environment by way of using e-mailing, forums, etc. As to the sources of professional information in English, it has already been remarked a number of times that at a university outside an Englishspeaking country authentic professional literature in English quite often is not abundant enough to satisfy all the requirements of a constructivist ESP course in authentic professional sources of information in English. Nothing but the Internet remains to provide students with the necessary abundance and variety of such sources.

Therefore, it may be said in conclusion that the Internet indeed creates the best support for successfully implementing experiential interactive teaching/ learning. It remains to discuss the impact of using Internet-based learning activities on implementing content-based instruction.

\section{Internet research as a means of implementing content-based instruction}

This issue does not need a detailed discussion because indirectly it has already been discussed in preceding section 3. Internet research helps in the implementation of content-based instruction simply because it provides the richest variety of content (professional) sources in English. Sometimes the Internet is practically the only place where the teachers and the students can get the professional content information that they need. But, on the other hand, the Internet research in the framework of a university ESP course has to meet four 
basic requirements to be able to provide for the implementation of contentbased (theme-based) instruction:

1. The sites chosen for students' Internet research need to be not only professional and target language ones but also authentic where the materials are prepared by native speakers for native speakers (see Chapter 4 for details concerning the notion of authenticity). Other materials, which are not authentic, cannot represent genuine communication samples characterizing the intercourse and interaction of specialists in a certain field. On the other hand, if such materials are authentic, they can be selected from those belonging to the genre of popular science too, and not only from the genre of academic science or from purely professional materials in the strictest sense of the word. As already said in Chapter 2, ESP courses are taught when students do not know much about their future specialty as yet. So, it is better to use the materials that are certain to be within the range of their comprehension, and popular science materials without a shadow of a doubt belong to that category. They are also close enough to strictly professional materials to teach the future profession via the medium of the target language. Besides, on professional Internet sites in English popular science materials are often in greater abundance than strictly professional ones - which facilitates selection.

2. The sites chosen for students' Internet research need to be theme-based, i.e., they are supposed to cover the professional themes that are selected for the ESP course. Students' Internet research should always be done in connection with such themes/topics because, if they start finding on the Internet and using in their ESP classes whatever disconnected professional materials in English, the structure of the course as a whole will be damaged, it will become unbalanced, and the distance between the pre-selected learning content and what is actually being learned will be gradually increasing - leading to moving far away from the pre-set goals of the course.

3. The sites chosen for students' Internet research need to be in great numbers and of great variety, so that different students have opportunities of working with different sites when researching materials on one and the same theme/topic, so as to be able to find different materials on that theme/topic. Otherwise (if students work with identical materials on the Internet), as already mentioned before, project work, work on preparing presentations, and other kinds of experiential learning activities are certain to become senseless. Students, when communicating on professional issues, will not be able to say anything new to each other after having obtained absolutely identical information from the Internet.

4. Everything said above in 1-3 emphasizes again the importance of the requirement to ESP teachers to collect their own Libraries of Internet sites 
which have already been discussed before. Without such a personal $\mathrm{Li}$ brary at every teacher's disposal from where they can always recommend as many sites as needed to their students, the Internet search done by those students may inevitably become chaotic. It will also greatly increase the time that they may need for finding the required information on the Internet - which is hardly acceptable for an ESP course with its time restraints, especially in the conditions when the substantial part of students' Internet research is done in class (c.f. above in this chapter). What has just been said does not mean that students should not find their own web-sites to do the Internet research and should use only the sites recommended by their teacher. On the contrary, finding some sites by learners themselves must always be a part of their Internet-based activities because it greatly motivates students by making their learning more creative. However, the realities of the teaching/learning process, especially the time restrictions in it, make independent search for web-sites only a part of Internet activities. They are to a considerable extent based on learners' work on the sites recommended by their teacher.

Following the requirements listed above can really provide for ensuring the content-based (theme-based) constituent of ESP teaching/learning process designed on the basis of the constructivist approach. This provision is guaranteed by introducing into such a process a great number and variety of authentic target language professional materials on the themes (topics) that have been selected for every particular ESP course. However, it is also clear from those requirements that as soon as the suggested approach has been brought to life, the Internet research done by the teacher will inevitably always be greater in volume than such research done by his or her students. The teacher's research is needed not only for creating his or her Library of Internet sites that has already been discussed a number of times. It is also needed for finding additional materials for students' reading and listening which can be copied and brought to class. Such a kind of research should be done by the teacher not just regularly but permanently practically before every class period of his or hers.

This requirement is due not only to the fact of frequent changes and renewals on Internet sites that have already been spoken about. It is even more due to the fact that it is on strictly professional and popular science Internet sites that the most recent information on the cutting edge developments in every particular field of knowledge is placed before that information appears anywhere else. Though sometimes such a kind of information found on the Internet is not sufficiently checked as yet and may later be discarded or refuted, however, for an ESP course it is often invaluable as a source for generating students' discussions, organizing their presentations, etc. This is because the cutting edge developments, which may still be little known to a lot of professionals, can interest and attract students much more than the universally known facts and ideas concerning their 
future specialty. So, the teacher simply has no right not to use such information in his or her experiential interactive theme-based classroom because it can raise the level of students' creativity in doing their learning assignments thanks to the enhancement of their learning motivation.

It should be noted that finding relevant professional and popular science Internet sites in English in whatever field cannot make any problems both for the teacher and the students if they have even beginners' skills in using such search engines as Google, Yahoo, or Yandex. Having found at least one professional or popular science site, the user is going to access a great number of links to other similar site and web-pages, thereby obtaining access to almost limitless sources of information on professional matters.

In general, in this and the preceding sections of this chapter the impact of Internet technologies on different constituents of the constructivist approach to ESP course design has been demonstrated. Such impact cannot but cause some modifications in the approach as a whole. The nature of those modifications is analyzed in the last section of the chapter.

\section{Internet technologies' impact on the constructivist approach to ESP course design}

If the approach to using Internet technologies discussed in the preceding sections of this chapter is followed, a qualitatively new teaching/learning process is obtained because students' work on the Internet permeates practically all its parts. This is why the constructivist approach, as described in Chapters 1 and 2, needs to be specified in view of the changes introduced into it by Internet-based learning activities described above.

In modern language teaching there are two fundamental approaches to broadly, systemically, and regularly (not episodically and unsystematically) using Internet technologies for ensuring students' better acquisition of the target language and communication in it: distance learning and blended learning.

Distance learning in foreign language teaching is not going to be analyzed at all in this monograph though a number of attempts have been made to introduce it into such teaching (Kerka, 1996; Murphy, 2007; NCSSFL Position Statement ..., 2011; Symposium on distance language learning, 2012; Trajanovic, Domazet, \& Misic-Ilic, 2007, and others). Distance learning in ESL/EFL is based on students' almost exclusively online out-of-class work with only episodic face-to-face meetings with the teacher and other students. Leaving aside the issue of how successful and adequate such learning is and can be, it may be said that it has no relation to the subject matter of our monograph because we are considering only those ESP courses at tertiary schools where the greater part of learning is 
done in class when students are in the company of their teacher and their peers.

As distinct from distance learning, blended learning, whose basics have already been discussed in the Introduction (2.2), is, according to Barrett and Sharma (2003: 39), a blend of different information sources that can be used in language teaching, so that traditional in-class learning and in-class and out-of-class learning with using innovative computer technologies can be united in a more or less balanced proportion. In their other work, totally devoted to blended learning, the same authors (Sharma, \& Barrett, 2007: 7) specify their understanding of such learning defining it as a language course uniting usual work in the classroom with the broadest use of the Internet, CD-ROMs, and other computer-based facilities in the language acquisition process. According to those authors, blended learning also presupposes the use of computers for communication via chat rooms, forums, and e-mails, thus creating virtual learning environments.

Blended learning has become very popular in some kinds of ESP teaching, especially in Business English studies (Sharma \& Barrett, 2007). It is radically different from a more traditional approach where information technologies are used as something supplementary but not as an integral and indispensable part in the course design. In fact, such technologies are something that may be used in the course for improving it but without which that course may exist and not suffer disintegration. Unlike this, in blended learning information technologies, and, first of all, the Internet, are organically built into the course design. We may speak about blended learning when students' work on the Internet is the source of numerous other learning assignments that can and are done without using computers but which cannot be done at all if the work on the Internet does not precede them. Since the assignments of that kind abound in the ESP course design analyzed in this monograph, we may call the approach advocated in it a blended learning one.

If speaking about the differences between blended learning and distance learning in greater detail, it should be noted that in blended learning computer-based work is not the focal one in the teaching/learning process. It is absolutely indispensable but it serves the others, non-computerized, kinds of learning activities, not dominating and prevailing over them as in distance learning. For instance, if the learning assignment is preparing a presentation, students collect the materials for that presentation on the Internet in and/or out of class (a computer-based activity), write the notes or the full text of the presentation (a computer-based activity if writing is done on a computer or a non-computerized activity if it is hand-written), and get ready for delivering it (a non-computerized activity). They also prepare illustrations for their presentation in PowerPoint (a computer-based activity). On this basis, they later orally deliver the presentation in class, answer the questions of other students, and have their presentation discussed by them (a non-computerized and focal activity). In the process of delivering the presentation, the students are using the illustrations in PowerPoint, etc. (a computer-based activity). It can be seen from this example 
how intertwined, interknit, or blended, computer-based and non-computerized learning activities are in blended learning.

Therefore, in blended learning, unlike distance learning, computer-based activities and the activities in face-to-face contacts of students and teachers are balanced with the view of better learners' target language communication and their improved language skills acquisition. This balancing means that all, computerized and non-computerized, kinds of learning activities are of equal importance and cannot exist without one another. From this point of view and from the examples of learning assignments that have been given in this chapter, it becomes clear that the approach advocated in the monograph is that of blended learning and in no way the one of distance learning.

The above mentioned balancing is the principal advantage of blended learning over both traditional learning and distance learning. Unlike traditional learning, that balancing allows using the full potential of computer/Internet technologies for improving the process of communication and language skills acquisition by learners. Unlike distance learning, it does not create 'the vacuum' of live target language communication between the teacher and the students and between the students themselves. Face-to-face contacts of the participants in the teaching and learning process remain intact with the consequent beneficial effect for the development of communication skills.

From the description of the blended learning given above and from what has been demonstrated in the preceding sections of this chapter, it can be seen how easily and organically blended learning combines itself with the constructivist approach embodied in experiential interactive teaching/learning and in content-based instruction. Students' continuously and autonomously work with computers, i.e., they use information technologies for researching professional issues (Internet research, preparing presentations, reports, doing project assignments on the basis of what has been found on the Internet, establishing virtual contacts with other people for doing project tasks, etc.). Subsequently, the obtained results are discussed in the classroom. That ensures profession-oriented content-based instruction in such activities as those above which closely resemble professional activities. Thanks to the latter feature (modeling professional activities) experiential learning is implemented - in the sense it is understood in this monograph and in the works by other authors (Cerdà, \& Williams, 2012; Freeman, \& Freeman, 1994). Finally, blended learning, organized as described, is going to be interactive in its very essence due to the interactive nature of students' work on the Internet (c.f. the examples above of pair and small group work when doing Internet-based assignments), thanks to the interaction with outside professional target language environment/outside professional target language sources of information when working there, and owing to learners' broad interaction when they are discussing what has been found during their Internet research. 
Everything said above allows two conclusions to be drawn:

1. Blended learning is organically combined with the constructivist approach making a unified constructivist blended learning approach out of two different approaches (the constructivist approach and the blended learning approach).

2. The method of using the Internet in an ESP course described in this chapter makes such a course a characteristic example of a blended learning ESP course design. The cause why blended learning is organically integrated into an ESP course design is due to the fact of students' work on the Internet becoming an integral and inalienable part of the process of their teaching and learning, so that the quality of that process is going to considerably deteriorate if Internet-based work is canceled. Internetbased activities are not something supplementary, as in a traditional ESP teaching/learning process. They become an indispensable and organically built-in component.

It should also be noted again that, as it can be seen from what has been said in Chapters 1 and 2, the constructivist approach can be implemented without blended learning. For instance, the approach followed when creating the coursebook Business Project (Tarnopolsky, Kozhushko, et al., 2002) was undoubtedly the constructivist one, fully corresponding to everything said about the practical implementation of that approach in Chapters 1 and 2. But that first version of the constructivist approach developed by us bore no traces of blended learning because in the years when the coursebook Business Projects was being created such learning was on the verge of emergence only but still remaining something not really developed or universally recognized. Therefore, the more traditional approach to involving the Internet in language studies was followed: using students' Internet research as a supplementary and optional activity without which the ESP/Business English course could function with no harm done or any serious problems caused.

In contrast, the second version of our constructivist approach embodied in the coursebook Psychological Matters (Tarnopolsky, Kozhushko, et al., 2011a) was already the one in which constructivism and blended learning were linked together so closely that they formed a single and inseparable unity where taking out one constituent, like students' Internet research (blended learning), would practically ruin the whole system. That can be seen from the practical examples of learning assignments and the system description given in this chapter. Just such absolute interdependence of constructivism and blended learning represents the fundamental modification, or change, that the introduction of blended learning generates in the constructivist approach. So, only this second version 
of the approach discussed in Chapter 3 of the monograph can be regarded as a constructivist blended learning ESP course, while the earlier first version embodied in Business Projects coursebook is simply a constructivist ESP course. As such, these two kinds of ESP courses will be positioned in the following chapters.

Having discussed in the first three chapters of the monograph the basics (both theoretical and practical) of the constructivist blended learning approach to teaching English for Specific Purposes at tertiary schools, some peculiarities of implementing the approach in teaching practice need to be analyzed. The first of such peculiarities is a set of totally practical principles that govern the implementation of the approach when practically designing an ESP course. Those principles are considered in the next chapter.

\section{Conclusion to Chapter 3}

In this chapter the notion of blended learning in ESP teaching and learning has been discussed. Blended learning is shown as the third fundamental constituent in the constructivist ESP course design - the constituent that is subordinated to the first two (experiential interactive teaching/learning and content-based instruction) and serves them with the purpose of improving their functioning.

Using computer technologies in general and Internet-technologies in particular as the basis of blended learning in ESL/EFL teaching/learning, especially in ESP teaching/learning, are analyzed. The range of various functions and roles that the Internet can play in improving ESP acquisition is also discussed. It has been demonstrated that students' Internet research on professional and popular science Internet sites in English is the principal, the most useful, and the most widely used of those functions. However, it is emphasized that other Internet functions, such as being a medium of virtual target language communication, being a place for publishing students' works in the target language, etc., should also be addressed in ESP courses, though, unlike Internet research, as optional and not mandatory ones.

The organizational structure of introducing Internet technologies into ESP courses is considered, and the conclusion is made that Internet research should be done by students both in and out of class with the in-class Internet research prevailing, especially at early stages of an ESP course. The general conclusion is drawn that the organizational structure of introducing Internet technologies presupposes the inclusion of students' Internet research as an absolutely mandatory learning activity into an ESP coursebook and ESP course as a whole.

The use of Internet research and other Internet-based learning activities for improving the process and results of experiential learning are analyzed, and the benefits of Internet for enhancing interactivity in the framework of experiential 
interactive ESP courses are manifested. The advantages of using Internet-based learning activities for improving the content-based instruction characteristic of a constructivist ESP course are also demonstrated.

The approach to involving Internet technologies in teaching ESP courses at tertiary schools suggested in the chapter has been shown as being a typical representative of blended learning approaches. That approach is demonstrated as ideal to be combined with the constructivist approach to an ESP course design forming a single constructivist blended learning approach. However, it is indicated that, though the constructivist blended learning approach is more advanced as compared with the per se constructivist approach to ESP teaching/ learning, the latter can exist and function successfully even without the blended learning component. 